\title{
First report of Nyssomyia whitmani (Antunes \& Coutinho, 1939) and Pintomyia fisheri (Pinto, 1926) in a transmission area of American cutaneuous Leishmaniasis, in south of Minas Gerais State, Brazil
}

\begin{abstract}
The epidemiology of American Cutaneous Leishmaniasis (ACL) is driven by the presence of vectors infecting humans with Leishmania spp parasites, in this way sand flies regarding to Lutzomyia genera. The emergence and re-emergence of this disease around the world calls for studies to identify geographical distribution of vectors and reservoir species associated with zoonotic transmission of the parasite. Although cases of ACL have been reported in Lavras, Minas Gerais State, Brazil, the epidemiological aspects of the disease remain unknown. In this way, an entomological survey of phlebotomine sand flies was carried out in the city, aiming at detecting the presence of potential vectors. HP traps light were able to capture a sample of phlebotomines composed of Nyssomyia whitmani (Antunes \& Coutinho) in the peridomiciliary of both urban and rural area. In other hand, Pintomyia fischeri (Pinto, 1926) and L. shannoni (Dyar, 1929) were collected just in the rural area of the municipality. Despite the low densities found, this is the first report of $N$. whitmani, the main vector of ACL and P. fischeri, a potential vector of ACL in the municipality of Lavras. The present record not only contributes to our knowledge of the geographical distribution of sand flies, but can also be used to understanding of the epidemiological aspects of the Leishmania transmission that can be used to design better vector control strategies to mitigate the incidence of ACL in endemic areas.
\end{abstract}

Keywords: leishmaniasis, sand fly, Minas Gerais, distribution
Volume 7 Issue 3 - 2018

\author{
Thales Augusto Barcante, ' Yuly Andrea \\ Caicedo Blanco, ${ }^{2}$ Richardson Costa \\ Carvalho,' Daniel Isnard Moulin Gomes,' \\ Leandro Mata da Rocha Melo,' Ingrid \\ Marciano Alvarenga, ${ }^{2}$ Tarcisio Freitas \\ Milagres, ${ }^{3}$ Joseane Camilla de Castro, ${ }^{3}$ Thiago \\ Pasqua Narciso, ${ }^{2}$ Joziana Muniz de Paiva \\ Barcante ${ }^{1,4}$ \\ 'Department of Health Sciences, Federal University of Lavras, \\ Brazil \\ ${ }^{2}$ Department of Veterinary Medicine, Federal University of \\ Lavras, Brazil \\ ${ }^{3}$ Department of Parasitology, Federal University of Minas Gerais, \\ Brazil \\ ${ }^{4}$ Coordination of Prevention of Endemias, Federal University of \\ Lavras, Brazil
}

\begin{abstract}
Correspondence: Joziana Muniz de Paiva Barcante, Department of Health Sciences, Post-graduation Program in Health Sciences, Federal University of Lavras, CEP 37200-000, Box Office 3037, Lavras, Minas Gerais, Brazil, Email joziana@ dsa.ufla.br
\end{abstract}

Received: February 21, 2018 | Published: June 042018

\section{Introduction}

In the New World, several phlebotomize species (Diptera: Psychodidae: Phlebotominae) are involved in the transmission of parasites belonging to genus Leishmania. In an interesting way, sandflies are adaptating to anthropic modifications. Some species which were restricted to their natural environment are now found near human dwellings, banana plantation and domestic animal shelters. In Brazil, American Coetaneous Leishmaniasis (ACL) is widely distributed, with several cases having been reported throughout the country. ACL generally affect the skin and mucosal membranes of several terrestrial mammals' species. The spectrum of disease includes diffuse cutaneous leishmaniasis, mucosal disease or single ulcerative lesions, circular with well-defined raised borders and a bed of granulation tissue. ${ }^{2}$ The etiological agents consist of different species of Leishmania, including $L$. (V.) braziliensis, $L$. (L.) mexicana, $L$. (V.) panamensis responsible for because the disease in the definite host through sandflies bites. ${ }^{3,4}$ During the period from 2004 to September 2013, the Vigilância Epidemiológica reported five cases of ACL, being two from rural area and three from urban areas in the municipality of Lavras. The patients' ages range from 30 to 81 years old. Due to the cases of ACL registered in Lavras, an entomological survey of phlebotomize sand flies was carried out in the city, aiming at detecting the presence of the vectors and to investigate the autochthony of the registered ACL cases. Knowledge about local sandflies fauna composition and behavior helps shed light on several aspects involved in the transmission of leishmaniasis and has been the focus of several investigations. ${ }^{1,5,6}$

\section{Material and methods}

Lavras is a city in Southern Minas Gerais state, Brazil; located at an altitude of $919 \mathrm{~m}$ (Figure 1). It has a population density of roughly 99,229 inhabitants and an area of the city is $564.7 \mathrm{~km}^{2}$ (IBGE 2014). The climate of the areas is of the Cwa type according to the Köppen classification, with an average annual temperature of $19^{\circ} \mathrm{C}$ and average annual rainfall of $1,530 \mathrm{~mm}$. In the soil sampling period, the temperature variation ranged from 10.0 to $33.8^{\circ} \mathrm{C}$ with an average temperature of $28^{\circ} \mathrm{C}$ and average precipitation of $14 \mathrm{~mm}$ (Meteorological Station of the Federal University of Lavras - UFLA). The town native vegetation is represented by a mosaic of different phytophysiognomies of forest and Cerrado, which have been partially by substituted by pastures and agricultural crops, only small fragments of native vegetation remaining, usually quite anthropized. ${ }^{7}$

The captures were undertaken by the teams from the Vigilância Ambiental and from the Laboratório de Biologia Parasitária of the Universidade Federal de Lavras (BIOPAR/UFLA), in October 2013. The entomological survey was performed during three consecutive nights for $12 \mathrm{~h}$ per night (6:00pm to 6:00am). Eight HP light traps were installed being four in a small property equipped with a chicken 
houses and a kennel with near 500 dogs located at the boundary of the highway area and a small forest (Figure 2). The others four traps were installed in an urban area nearby chicken houses (Figure 2). The second and most current source of information for the sand flies classification of the New World was proposed by Galati, ${ }^{8}$ which uses 88 morphological characters in an attempt to resolve the characterization of sand flies. All collected phlebotomies were identified according to the Galati classification system.8 Females were identified by transferring the guts of the sand flies to a drop of buffered saline on a microscope slide using a pair of mounted entomological pins. A cover slip was then placed over the drop and the thorax, sperm thecae and ciborium were examined under an optical microscope. The male specimens were prepared and mounted. A cover slip was then placed over the drop and the thorax and ciborium were examined under an optical microscope.

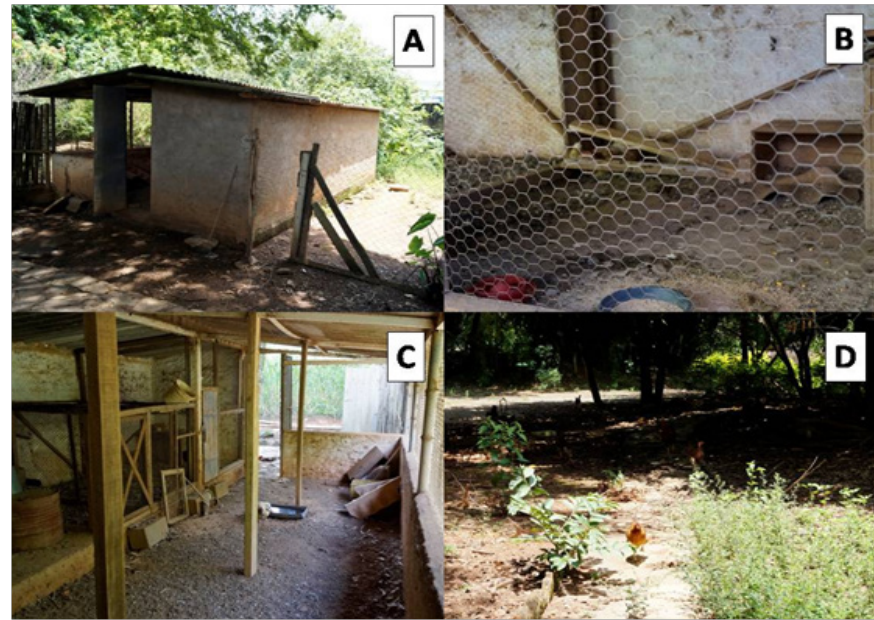

Figure I Places were sand flies were collected.

(A-D) Places near chicken house in the urban area of the Municipality of Lavras, Minas Gerais State, Brazil.

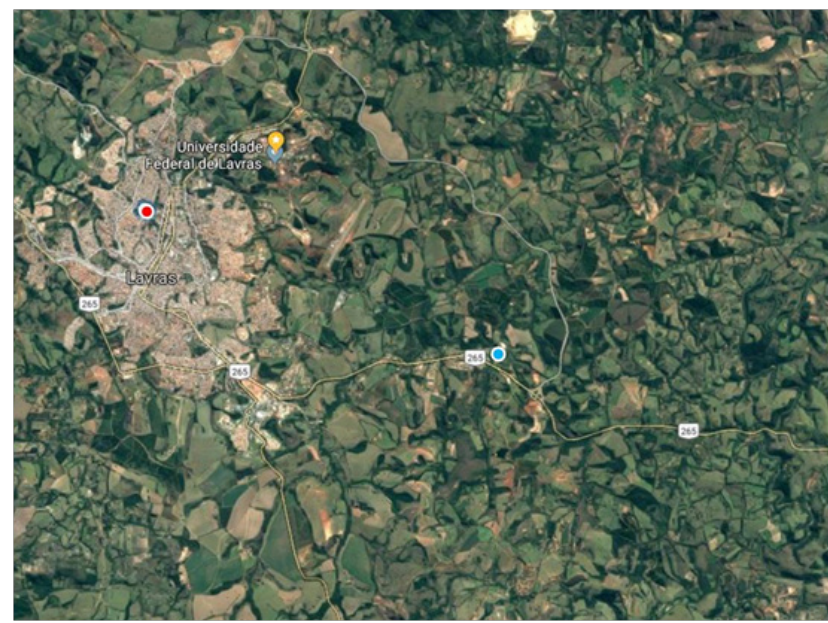

Figure 2 Spatial distribution of the entomological trapping sites in the urban area (red) and rural area (blue) of Lavras (Minas Gerais State, Brazil). The study was conducted September and October 2013.

\section{Results and discussion}

During the period of September 2013 to October 2013, a total of 10 phlebotomies were collected and identified as presented in Table 1. Six specimens ( 3 male and 3 female) collected in the urban area were identified as belonging to the species $L$. (N.) whitmani, all of them being from the chicken houses (Figure 3). Barretto ${ }^{9}$ in his entomological studies in São Paulo, Brazil, considered $L$. (N.) whitmani as a silvatic species, although it could be found inside houses that were situated within or near the forest. At dusk it was found biting man, in addition to feeding on dogs and was shown to be present in large numbers in chicken houses. $^{4}$

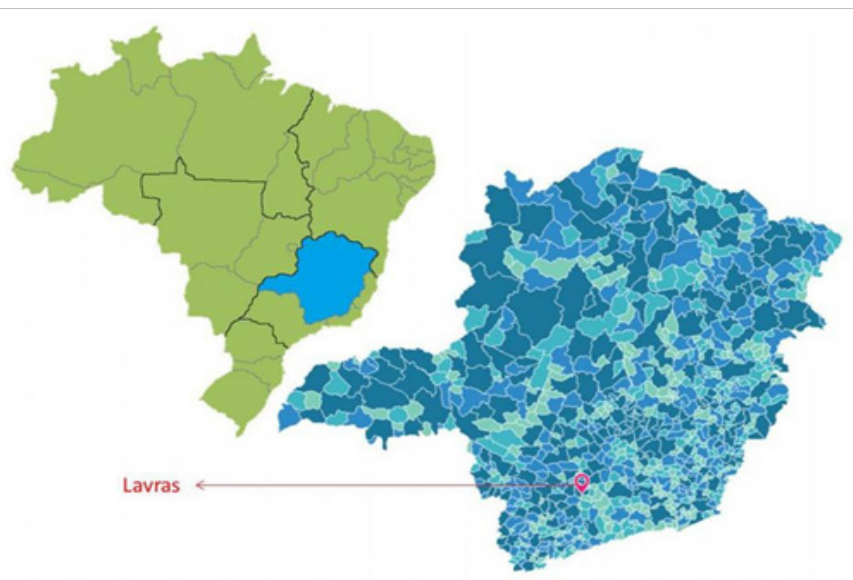

Figure 3 Map of Brazil, with emphasis on the state of Minas Gerais, where the specimens of sand flies were collected. The map also displays the Municipality of Lavras where the specimens were collected.

Nowadays, this sand fly is suggested to be the most important vector of ACL in Brazil. ${ }^{3}$ It has been recorded in a large number of endemic areas and in association with wide vegetation diversity. ${ }^{4}$ The aforesaid alterations in ecology, together with climatic changes, most probably account for the spread of ACL in Brazil in recent years. ${ }^{10}$ Similar to the observed by Costa et al., ${ }^{4}$ and Shaw,${ }^{11}$ in this report $N$. whitmani appears to be a sand fly which adapts to new environments, such as degraded areas, in association with domestic animals and man in rural and urban areas. In the rural area, two different species of phlebotomies were collected near the kennel. P. fischeri has been registered in the Brazilian States of Central-east, Northeast, Southeast and South regions of the country. Lainson (1983), considering the abundance of this sandfly in deforested ACL areas, suggested that this species must be adapted to environmental changes, maintaining the transmission of $L$. (V.) braziliensis among wild animals in the secondary forested areas. This species has been adapting to per domestic rural habitats since 1953, reported to inhabit proximities of domestic animal shelters. ${ }^{4,5}$ Recently, P. fischeri has been found naturally infected by $L$. (V.) braziliensis. ${ }^{12}$ Although $P$. fischeri present an anthropophagic behavior, there is some discussion concerning its preference for feeding on dogs and chickens. ${ }^{13-15}$ In the present study, $P$. fischeri was collected only in the rural area, near the kennel and chicken houses. 


\section{Conclusion}

Despite the low densities found, this is the first report of $N$. whitmani, the main vector of $\mathrm{ACL}^{3}$ and $P$. fischeri, a potential vector of ACL in the municipality of Lavras. The present record not only contributes to our knowledge of the geographical distribution of sand flies, but can also be used to design better vector control strategies to mitigate the incidence of ACL in endemic areas.

\section{Acknowledgements}

This work was supported by the Minas Gerais Research Support Foundation (APQ 02553-14), National Council of Scientific and Technological Development, Brazil and CAPES.

\section{Conflict of interest}

Author declares there is no conflict of interest.

\section{References}

1. Ximenes MF, Souza MF, Castell'on EG. Density of sand flies (Diptera: Psychodidae) in domestic and wild animal shelters in an area of visceral leishmaniasis in the state of Rio Grande do Norte, Brazil. Mem Inst Oswaldo Cruz. 1999;94(4):427-432.

2. Bernardo G, Carvalho MLR. Leishmaniose tegumentar americana. Rev Soc Bras Med Trop. 2003;36(1):71-80.

3. Barreto MB, Carneiro AL, Torres FAG, et al. Lutzomyia whitmani is the main vector of American Cutaneous Leishmaniasis in the Brazilian Federal District and the most prevalent species in residential areas of the Administrative Region of Sobradinho. An Bras Dermatol. 2014;89(2):372-374.

4. Costa SM, Cechinel M, Bandeira V, et al. Nyssomyiawhitmanis (Antunes \& Coutinho, 1939) (Diptera: Psychodidae: Phlebotominae) and the epidemiology of American cutaneous leishmaniasis in Brazil. Mem Inst Oswaldo Cruz. 2007;102(2):149-153.

5. Aguiar GM, Soucasaux T. Ecological aspects of phlebotomus of the parque nacional da serra dos Orgãos, Rio de Janeiro. I. Monthly frequency in human baits (Diptera, Psychodidae, Phlebotominae). Mem Inst Oswaldo. 1984;79(2):197-209.
6. Kuhls K, Alam MZ, Cupolillo E, et al. Comparative microsatellite typing of new world Leishmaniain infantum reveals low heterogeneity among populations and its recent old world origin. PLoS Negl Trop Dis. 2011;5(6):e1155.

7. Gomide PHO, Silva MLN, Castro GC, et al. Vegetation characterization in gully areas as basis for soil conservation. Cienc Agrotec. 38(2):149159.

8. Galati EAB. Morfologia e Taxonomia. In: Rangel EF, Lainson R, editors. Flebotomíneos do Brasil. Rio de Janeiro: Fiocruz; 2003. p. 23-51.

9. Barretto MP. Observações sobre a biologia em condições naturais dos flebótomos do estado de São Paulo (Ditera: Psychodidae). Faculdade de Medicina da USP: São Paulo; 1943.

10. Shaw J. The leishmaniasis-survival and expansion in a changing world. A mini-review. Mem Inst Oswaldo Cruz. 2007;102(5):541-547.

11. Shaw J. How climatic and environmental variations affect the ecoepidemiology of the leishmaniasis and their control. $3^{\text {rd }}$ Workshop on Genetics and Molecular Biology of Tropical Disease Vector Insects. 2008. 13 p.

12. Rocha LS, Falqueto A, Santos CB, et al. Survey of natural infection by Leishmania in sand fly species collected in southeastern Brazil. Trans $R$ Soc Trop Med Hyg. 2010;104(7):461-466.

13. Souza NA, CA Andrade-Coelho CA, Vilela ML. Seasonality of Lutzomyia intermedia and Lutzomyia whitmani (Diptera: Psychodidae: Phlebotominae), occurring sympatrically in area of cutaneous leishmaniasis in the state of Rio de Janeiro, Brazil. Mem Inst Oswaldo Cruz. 2002;97(6):759-765.

14. Rangel EF, Lainson R. Proven and putative vectors of American cutaneous leishmaniasis in Brazil: aspects of their biology and vectorial competence. Mem Inst Oswaldo Cruz. 2009;104(7):937-954.

15. Salom'on OD, Rossi GCi, Cousiño B, et al. Phlebotominae sand flies in Paraguay. Abundance distribution in the Southeastern region. Mem Inst Oswaldo Cruz. 2003;98:185-190. 